\title{
Comparison of intra-articular versus intravenous application of tranexamic acid in total knee arthroplasty: a meta-analysis of randomized controlled trials
}

\author{
Yaming Liu, Fantao Meng, Gang Yang, Lingde Kong, Yong Shen
}

Department of Orthopedics, The Third Hospital of Hebei Medical University, Shijiazhuang, Hebei, China

Submitted: 9 May 2015

Accepted: 27 June 2015

Arch Med Sci 2017; 13, 3: 533-540

DOI: https://doi.org/10.5114/aoms.2017.67278

Copyright $\odot 2017$ Termedia \& Banach

\section{Abstract}

Introduction: There is much controversy about the optimal application of tranexamic acid (TXA) in total knee arthroplasty (TKA). The purpose of this meta-analysis was to compare the efficacy of the intra-articular and intravenous regimens of TXA in TKA.

Material and methods: A literature search of the PubMed, Embase and Cochrane Library databases was performed. Randomized controlled trials comparing the result of intra-articular and intravenous application of TXA during TKA were included. The focus was on the outcomes of blood loss, transfusion requirement and thromboembolic complications.

Results: Six studies were eligible for data extraction and meta-analysis. We found no statistically significant difference between intra-articular and intravenous administration of tranexamic acid in terms of total blood loss (WMD, 6.01; 95\% Cl: -96.78 to $108.79 ; p=0.91)$, drain output (WMD = $-20.26 ; 95 \% \mathrm{Cl}:-51.34$ to $10.82 ; p=0.20)$, hemoglobin drop $(\mathrm{WMD}=0.33$; $95 \% \mathrm{Cl}:-0.31$ to $0.98 ; p=0.31)$, or the incidences of transfusion $(\mathrm{RR}=0.98$; $95 \% \mathrm{Cl}: 0.56-1.70 ; p=0.93)$ as well as deep vein thrombosis $(\mathrm{RR}=0.49$; $95 \% \mathrm{Cl}: 0.09-2.73 ; p=0.42$ ).

Conclusions: In comparison with intravenous application of TXA, intra-articular application had a comparable effect on reducing blood loss and the transfusion rate without increasing the complication rate.

Key words: tranexamic acid, intra-articular, intravenous, total knee arthroplasty, meta-analysis.

\section{Introduction}

With the aging of the population, the number of patients with osteoarthritis of the knee has increased dramatically. In patients with severe osteoarthritis, total keen arthroplasty (TKA) is widely used as an effective method to relieve pain, correct deformity, and restore function. However, because of the large exposed surface of cancellous bone, intraoperative and postoperative bleeding is one of the major complications following TKA $[1,2]$. There is no doubt that a large amount of blood loss has a significant influence on morbidity and mortality, especially in old patients [3, 4]. Thus, seeking an effective method to reduce the loss of blood is necessary.

Tranexamic acid (TXA), as an antifibrinolytic agent, was introduced with the aim of reducing perioperative and postoperative bleeding. It

\author{
Corresponding author: \\ Yong Shen \\ Department of Orthopedics \\ The Third Hospital of \\ Hebei Medical University \\ 139 Ziqiang Road \\ Shijiazhuang \\ Hebei 050051, China \\ Phone: +86031188602316 \\ Fax: +86031188602016 \\ E-mail: shenyongspine@126. \\ com
}


can block the lysine binding sites on plasminogen molecules, inhibit the formation of plasmin, and is believed to be able to help the body retain blood clots more effectively [5].

The intravenous application of TXA in orthopedic surgery has been well established in the literature. Many clinical studies and several meta-analyses have confirmed that this way could effectively reduce the rates of blood loss and transfusion in TKA without increasing the risk of complications [6-10]. In comparison with intravenous application, the intra-articular application of TXA has the advantages of being easy to administer, providing a maximum concentration of TXA at the bleeding site, and being associated with lower systemic absorption [11]. In recent years, intra-articular application of TXA has been put under the spotlight. However, based on current evidence, it is not clear whether intra-articular application of TXA is as effective as intravenous application measures.

Therefore, we conducted a systematic review and meta-analysis to compare intra-articular and intravenous administration of TXA in terms of blood loss, transfusion requirement and thromboembolic complications.

\section{Material and methods}

\section{Literature search and inclusion criteria}

PubMed, Embase and Cochrane Library databases were searched for randomized controlled trials (RCTs) that have been published from inception to March 2015. The following format of search terms was used: ('knee' or 'joint') and ('arthroplasty' or 'replacement') and 'tranexamic acid'. Search results were limited to human subjects, and no language restriction was imposed. We also manually checked the reference lists of RCTs in order to include other potentially eligible trials. The following inclusive selection criteria were applied: (a) study design: randomized controlled trials (RCT); (b) study population: adult patients receiving TKA; (c) intervention group: intra-articular application of TXA; (d) control group: intravenous application of TXA; and (e) outcome measure: total blood loss, drain output, hemoglobin drop, and incidents of transfusion, deep vein thrombosis (DVT) and pulmonary embolism (PE).

\section{Data extraction and outcome measures}

General characteristics and measured outcomes from each RCT were extracted independently by two authors. General characteristics included first author, publication year, country, number of patients (intervention/control group), and TXA dosage. Measured outcomes included total blood loss, drain output, hemoglobin drop, and the incidence of transfusion, DVT and PE. For continu- ous outcomes, if a group was divided into several subgroups, we combined numbers into a single sample size, and calculated means and standard deviations by the method introduced by the Cochrane Handbook [12]. When the same population was reported in several publications, we retained the most informative article or complete study to avoid duplication of information. Any disagreements were resolved by discussion and consensus.

\section{Assessment of methodological quality}

The methodological quality of these studies was evaluated without masking the trial names. Reviewers followed the instructions provided in the Cochrane Handbook for Systematic Reviews of Interventions [12]. A total of seven domains were assessed: random sequence generation, allocation concealment, blinding of participants and personnel, blinding of outcome assessment, incomplete outcome data, selective reporting, and other bias. If the information in a study was inadequate, we attempted to contact the authors in order to evaluate the study correctly.

\section{Statistical analysis}

Differences were expressed as risk ratios (RRs) with 95\% confidence intervals (Cls) for dichotomous outcomes and weighted mean differences (WMDs) with $95 \%$ Cls for continuous outcomes. Heterogeneity was analyzed with both the $\chi^{2}$ test and the $l^{2}$ test. A $p$-value of $<0.10$ for the $\chi^{2}$ test was interpreted as evidence of statistical heterogeneity, and $l^{2}$ was used to estimate total variation across the studies. Studies with an $R$ statistic of 25-50\% were considered to have low heterogeneity, those with an $R^{2}$ statistic of $50-75 \%$ had moderate heterogeneity, and those with an $l^{2}$ statistic of $>75 \%$ had high heterogeneity. The random effects model was used to pool RRs or WMDs in the case of significant heterogeneity ( $p<0.10$ or $R^{2}>50 \%$ ); otherwise, a fixed-effects model was used.

Because patient characteristics, TXA dosage, and other confounding factors were not consistent among studies, we further conducted sensitivity analysis to identify potential sources of heterogeneity.

The presence of publication bias was assessed by the Begg and Egger tests. A p-value $<0.05$ was regarded as statistically significant, except where otherwise specified. All statistical analyses were performed using Review Manager Version 5.1 (The Cochrane Collaboration, Software Update, Oxford, UK).

\section{Results}

\section{Literature search results}

After the initial database search, a total of 113 records were identified. However, on the basis of 
the titles and abstracts, 45 records were excluded because of duplicate studies and 54 were excluded for other reasons, such as reviews, non-randomized studies, or not relevant to our analysis. The remaining 14 were retrieved for full text review, but 8 of them were excluded because 5 did not report outcomes of interest, and 3 were cohort studies. Finally, 6 RCTs that met our inclusion criteria were included in the present meta-analysis [8, 13-17] The selection process is shown briefly in Figure 1.

\section{Study characteristics}

The main characteristics of the 6 RCTs included in the meta-analysis are presented in Table I. All these studies were in English and published between 2012 and 2014. The populations of the RCTs ranged from 60 to 200 cases. There were a total of 676 patients involved. Among them, 305 were the intra-articular group and 371 were the intravenous group. All patients were diagnosed with osteoarthritis and underwent TKA. The dose of intra-articular application of TXA ranged from
$1.5 \mathrm{~g}$ to $3 \mathrm{~g}$ and the intravenous application ranged from single-dose to triple-dose.

\section{Assessment of risk of bias}

The risk of bias is demonstrated graphically in Figure 2 and summarized in Figure 3. The randomization technique was mentioned in all 6 trials. However, only 2 trials described the process of random sequence generation [14, 16], and 2 trials stated the method of allocation concealment [8, 13]. Blinding of participants and personnel was used in 4 trials [8, 13-15], but none of the studies was blinded in the assessment of outcome. One trial was judged to be at low risk of attrition bias [13], and 5 were at low risk of reporting bias [13-17].

\section{Outcome}

\section{Total blood loss}

Two studies reported the data on total blood loss. The test for heterogeneity was not significant, and the studies have no statistical evidence

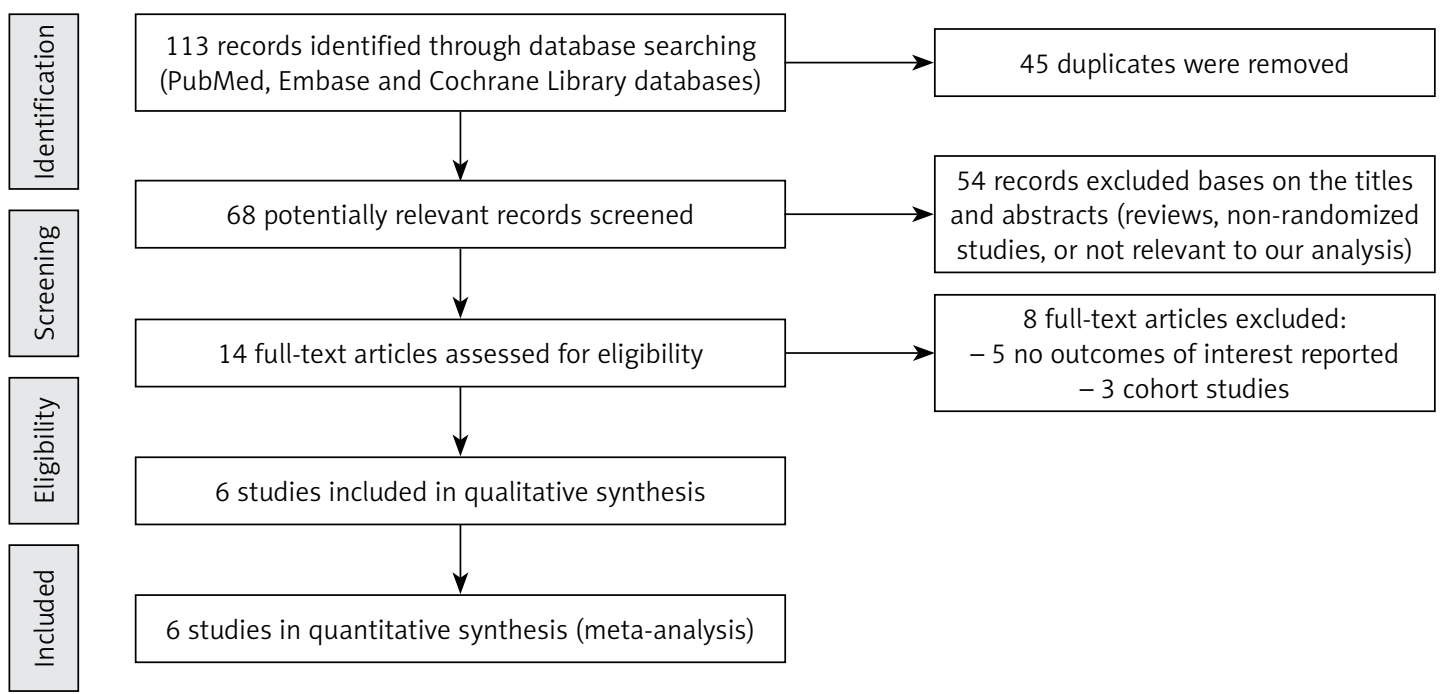

Figure 1. Preferred reporting items for systematic reviews and meta-analyses (PRISMA) flow diagram outlining literature search results

Table I. Characteristics of the included studies

\begin{tabular}{|lcccccc|}
\hline Author & $\begin{array}{c}\text { Publication } \\
\text { year }\end{array}$ & Country & \multicolumn{2}{c|}{ Number of patients } & \multicolumn{2}{c|}{ TXA dosage } \\
\cline { 3 - 7 } & & & $\begin{array}{l}\text { Intra-articular } \\
\text { group }\end{array}$ & $\begin{array}{l}\text { Intravenous } \\
\text { group }\end{array}$ & Intra-articular group & Intravenous group \\
\hline Maniar [8] & 2012 & India & 40 & 160 & $3 \mathrm{~g}$ TXA/100 ml NS & $10 \mathrm{mg} / \mathrm{kg} \times(1-3) \mathrm{dose}$ \\
\hline Seo [16] & 2013 & Korea & 50 & 50 & $1.5 \mathrm{~g} \mathrm{TXA} / 100 \mathrm{ml} \mathrm{NS}$ & $1.5 \mathrm{~g} \mathrm{TXA} / 100 \mathrm{ml} \mathrm{NS}$ \\
\hline Soni [17] & 2014 & India & 30 & 30 & $3 \mathrm{~g} \mathrm{TXA} / 100 \mathrm{ml} \mathrm{NS}$ & $10 \mathrm{mg} / \mathrm{kg} \times 3$ dose \\
\hline Sarzaeem [15] & 2014 & Iran & 100 & 50 & $3 \mathrm{~g}$ TXA/100 ml NS & $1.5 \mathrm{~g} \mathrm{TXA} / 100 \mathrm{ml}$ NS \\
\hline Patel [14] & 2014 & USA & 46 & 42 & $2 \mathrm{~g}$ TXA/100 ml NS & $10 \mathrm{mg} / \mathrm{kg} \times 1$ dose \\
\hline $\begin{array}{l}\text { Gomez-Barrena } \\
{[13]}\end{array}$ & 2014 & Spain & 39 & 39 & $3 \mathrm{~g}$ TXA/100 ml NS & $15 \mathrm{mg} / \mathrm{kg} \times 1$ dose \\
\hline
\end{tabular}

TXA - tranexamic acid, NS - normal saline. 
Random sequence generation (selection bias)

Allocation concealment (selection bias)

Blinding of participants and personnel (performance bias)

Blinding of outcome assessment (detection bias)

Incomplete outcome data (attrition bias)

Selective reporting (reporting bias)

Other bias

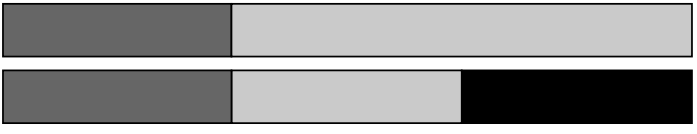

\section{.}
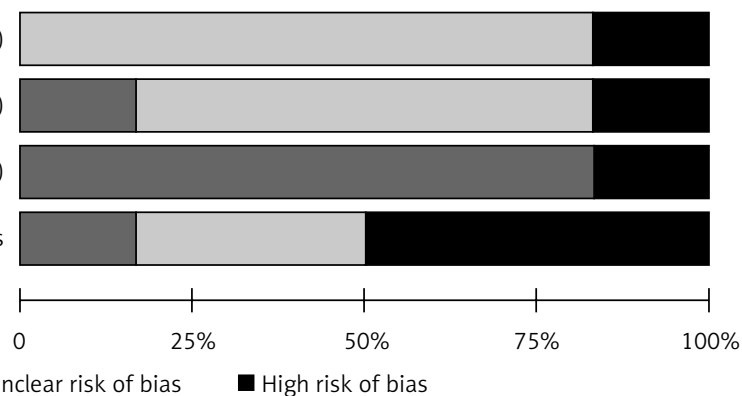

$\square$ Low risk of bias

$\square$ Unclear risk of bias

High risk of bias

Figure 2. Risk of bias graph: a review of the authors' judgments regarding each risk of bias item, presented as percentages across all included studies

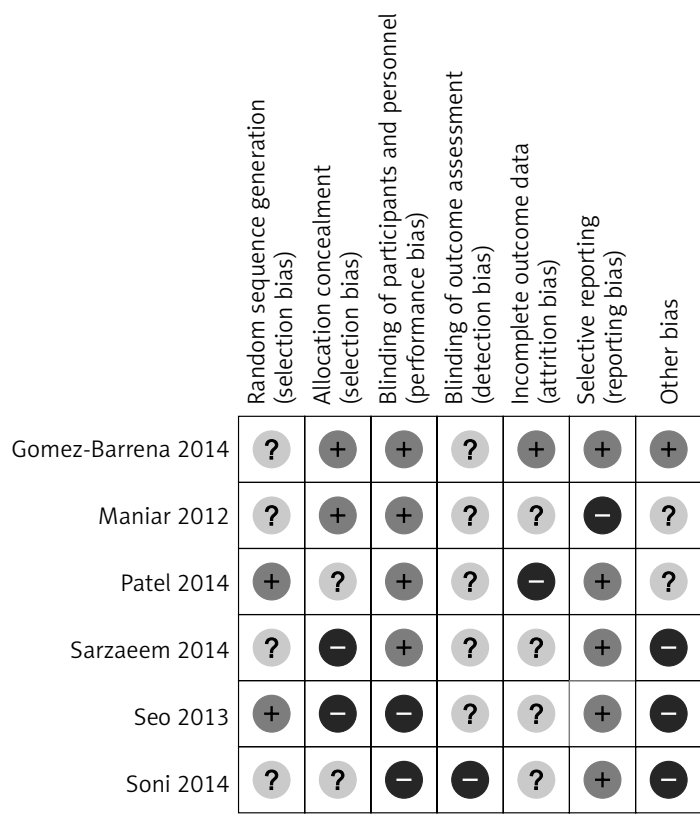

Figure 3. Risk of bias summary: a review of the authors' judgments regarding each risk of bias item for each included study

of heterogeneity ( $p$ for heterogeneity $=0.60$; $\left.R^{2}=0 \%\right)$. Using the fixed-effect model, there was no significant difference in total blood loss between the two groups (WMD, 6.01; 95\% Cl: -96.78 to $108.79 ; p=0.91$ ) (Figure 4 ).

\section{Drain output}

Data on drain output were available for 5 trials. The test for heterogeneity was not significant, and the studies have no statistical evidence of heterogeneity $\left(p\right.$ for heterogeneity $=0.66 ; l^{2}=0 \%$ ). Using the fixed-effect model, the aggregated results suggested that there was no significant difference in drain output between the two groups (WMD = -20.26 ; $95 \% \mathrm{Cl}:-51.34$ to $10.82 ; p=0.20$ ) (Figure 5). Excluding any single study did not materially alter the overall combined WMD, which ranged from -6.92 ( $95 \% \mathrm{Cl}:-48.31$ to $34.47 ; p=0.74$ ) to $-24.53(95 \% \mathrm{Cl}:-56.32$ to $7.27 ; p=0.13)$.

\section{Hemoglobin drop}

A reduction in hemoglobin after surgery was reported in 5 studies. There was high statistical heterogeneity among the studies ( $p$ for heterogeneity $\left\langle 0.01 ; I^{2}=94 \%\right.$ ). Pooling the data with a random-effect model revealed no statistically significant difference between the intra-articular group and the intravenous group ( $\mathrm{WMD}=0.33$; $95 \% \mathrm{Cl}:-0.31$ to $0.98 ; p=0.31$ ) (Figure 6). Excluding any single study did not materially alter the overall combined WMD, which ranged from 0.03 ( $95 \% \mathrm{Cl}:-0.24$ to $0.30 ; p=0.82)$ to $0.47(95 \% \mathrm{Cl}$ : -0.29 to $1.22 ; p=0.22$ ), but excluding the trial conducted by Sarzaeem et al. [15] decreased the $I^{2}$ from $94 \%$ to $53 \%$.

\begin{tabular}{|c|c|c|c|c|c|c|c|c|c|c|c|}
\hline \multirow{2}{*}{$\begin{array}{l}\text { Study or } \\
\text { subgroup }\end{array}$} & \multicolumn{3}{|c|}{ Intra-articular } & \multicolumn{3}{|c|}{ Intravenous } & \multirow{2}{*}{$\begin{array}{c}\text { Weight } \\
(\%)\end{array}$} & \multirow{2}{*}{$\begin{array}{c}\text { Mean difference } \\
\text { IV, fixed, } 95 \% \mathrm{Cl} \text {, year }\end{array}$} & \multirow{2}{*}{\multicolumn{3}{|c|}{$\begin{array}{l}\text { Mean difference } \\
\text { IV, fixed, } 95 \% \mathrm{CI}\end{array}$}} \\
\hline & Mean & SD & Total & Mean & SD & Total & & & & & \\
\hline Maniar 2012 & 809 & 341.1 & 40 & 789.5 & 279.1 & 160 & 81.0 & $19.50(-94.71,133.71) 2012$ & & & \\
\hline Gomez-Barrena & $1,574.5$ & 542.9 & 39 & 1,626 & 519.2 & 39 & 19.0 & $-51.50(-287.26,184.26) 2014$ & & & \\
\hline \multicolumn{12}{|l|}{2014} \\
\hline Total $(95 \% \mathrm{Cl})$ & & & 79 & & & 199 & 100.0 & $6.01(-96.78,108.79)$ & & & \\
\hline \multicolumn{9}{|c|}{ Heterogeneity: $\chi^{2}=0.28, \mathrm{~d} f=1(p=0.60), I^{2}=0 \%$} & -200 & -100 & 200 \\
\hline \multicolumn{9}{|c|}{ Test for overall effect: $Z=0.11(p=0.91)$} & ours exp & erimental Favours & ontrol \\
\hline
\end{tabular}

Figure 4. Forest plot showing the comparison of total blood loss between the intra-articular group and the intravenous group 


\begin{tabular}{|c|c|c|c|c|c|c|c|c|c|}
\hline \multirow{2}{*}{$\begin{array}{l}\text { Study or } \\
\text { subgroup }\end{array}$} & \multicolumn{3}{|c|}{ Intra-articular } & \multicolumn{3}{|c|}{ Intravenous } & \multirow{2}{*}{$\begin{array}{c}\text { Weight } \\
(\%)\end{array}$} & \multirow{2}{*}{$\begin{array}{c}\text { Mean difference } \\
\mathrm{IV} \text {, fixed, } 95 \% \mathrm{Cl} \text {, year }\end{array}$} & \multirow{2}{*}{$\begin{array}{l}\text { Mean difference } \\
\text { IV, fixed, } 95 \% \mathrm{CI}\end{array}$} \\
\hline & Mean & SD & Total & Mean & SD & Total & & & \\
\hline Maniar 2012 & 206.5 & 106.6 & 160 & 244 & 142.2 & 40 & 43.6 & $-37.50(-84.56,9.56) 2012$ & -+ \\
\hline Patel 2014 & 630.2 & 331.6 & 46 & 558.7 & 370.3 & 42 & 4.4 & $71.50(-75.89,218.89) 2014$ & \\
\hline Soni 2014 & 386.5 & 89.08 & 30 & 409.5 & 185.82 & 30 & 17.8 & $-23.00(-96.74,50.74) 2014$ & \\
\hline Sarzaeem 2014 & 458.5 & 300.6 & 100 & 476.8 & 114.8 & 50 & 21.5 & $-18.30(-85.26,48.66) 2014$ & \\
\hline $\begin{array}{l}\text { Gomez-Barrena } \\
2014\end{array}$ & 315.6 & 207.1 & 39 & 308.1 & 186.5 & 39 & 12.6 & $7.50(-79.97,94.97) 2014$ & \\
\hline Total $(95 \% \mathrm{Cl})$ & & & 375 & & & 201 & 100.0 & $-20.26(-51.34,10.82)$ & \\
\hline \multicolumn{9}{|c|}{ Heterogeneity: $\chi^{2}=2.40, \mathrm{~d} f=4(p=0.66), I^{2}=0 \%$} & $0-100 \quad 0 \quad 10020$ \\
\hline
\end{tabular}

Figure 5. Forest plot showing the comparison of drain output between the intra-articular group and the intrave-

nous group

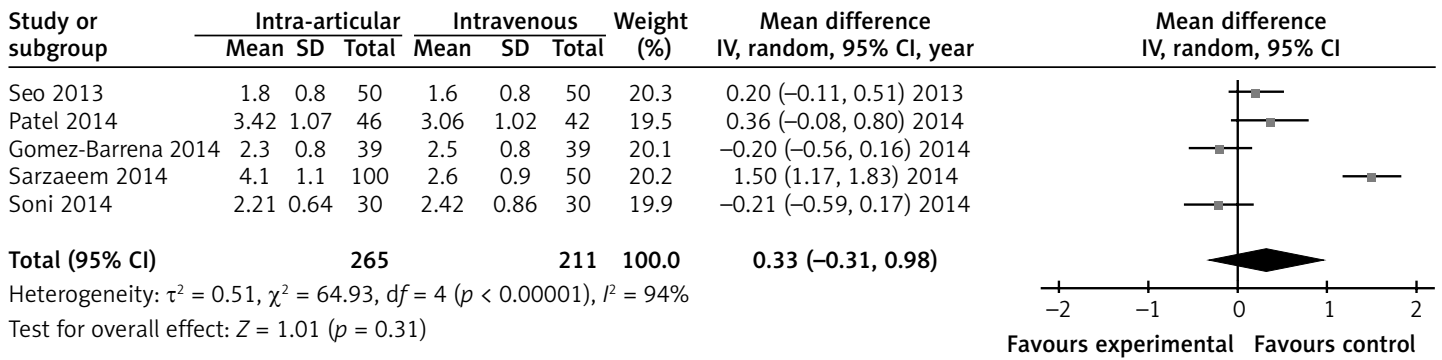

Figure 6. Forest plot showing the comparison of hemoglobin drop between the intra-articular group and the in-

travenous group

\section{Transfusion requirement}

All 6 studies provided data on the number of patients who needed a blood transfusion. In the intra-articular group, transfusions were found in 29 of 305 patients (9.5\%), and in the intravenous group they were found in 43 of 371 patients (11.6\%). The test for heterogeneity was not significant, and the studies have low statistical heterogeneity ( $p$ for heterogeneity $=0.23$; $P^{2}=28 \%$ ). Using the fixed-effect model, the rate of transfusion requirements was not significantly different between the intra-articular group and the intravenous group $(\mathrm{RR}=0.98 ; 95 \% \mathrm{Cl}$ : $0.56-1.70 ; p=0.93$ ) (Figure 7). Excluding any combined $\mathrm{RR}$, which ranged from $0.75(95 \% \mathrm{Cl}$ : $0.41-1.37 ; p=0.34)$ to 1.55 (95\% Cl: $0.75-3.17$; $p=0.23)$, but excluding the trial conducted by Sarzaeem et al. [15] decreased the $l^{2}$ from $28 \%$ to $0 \%$. single study did not materially alter the overall

\section{DVT}

All 6 studies provide data on the incidence of DVT after surgery. In the intra-articular group, DVT was found in 1 of 305 patients (0.3\%), and in the intravenous group it was found in 3 of 371 patients $(0.8 \%)$. There was low statistical heterogeneity among the studies ( $p$ for heterogeneity = $0.16 ; l^{2}=49 \%$ ). Using the fixed-effect model, there was no significant difference in the incidence of DVT between the two groups ( $R R=0.49 ; 95 \% \mathrm{Cl}$ : $0.09-2.73 ; p=0.42$ ) (Figure 8). Excluding any single study did not materially alter the overall combined $\mathrm{RR}$, which ranged from 0.13 (95\% Cl: 0.01-2.67; $p=0.19)$ to 3.08 (95\% Cl: $0.12-77.91 ; p=0.50)$.

\section{PE}

Data on PE were reported in 5 studies. There was no incident of PE in any study. Thus, no statistical analysis was performed.

Odds ratio M-H, fixed, $95 \% \mathrm{Cl}$, year

Odds ratio

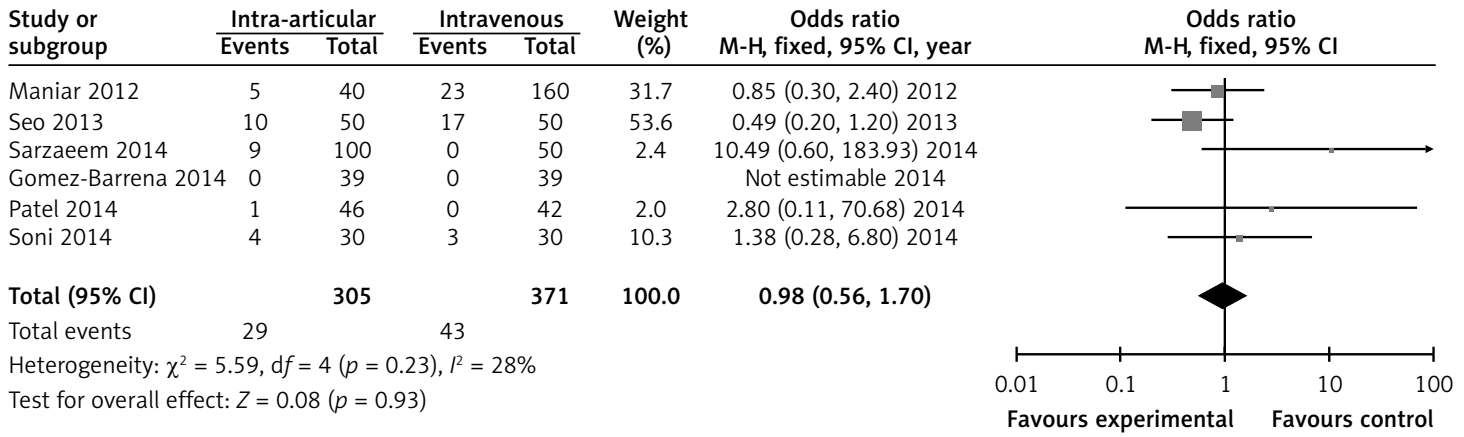

Figure 7. Forest plot showing the rate of transfusion requirement between the intra-articular group and the intravenous group 


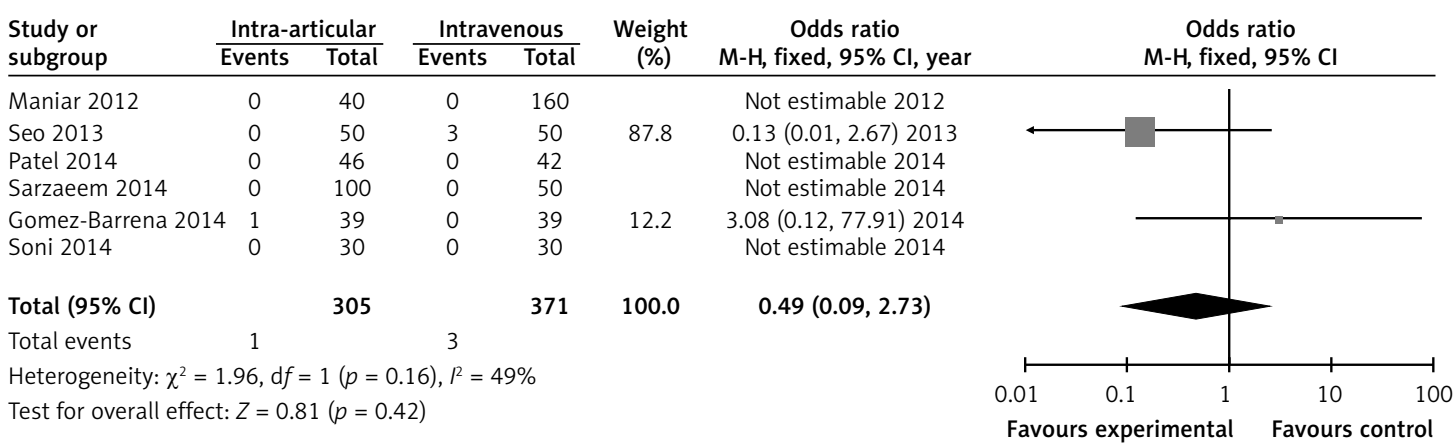

Figure 8. Forest plot showing the rate of deep vein thrombosis between the intra-articular group and the intravenous group

\section{Publication bias}

Because of the limited number $(<10)$ of studies included in each analysis, we did not assess publication bias.

\section{Discussion}

Blood loss is a major concern both during and after TKA surgery $[1,2]$. The TXA, as a synthetic antifibrinolytic agent, has been found to effectively reduce blood loss and the need for transfusion [5]. However, there is no consensus regarding the most effective regimen for TXA administration. Meta-analysis, as an efficient method to integrate valid information, can provide a basis for making a clinical decision [18-20]. In the current study, we included all available RCTs, and performed a meta-analysis. The pooled results revealed that there were no statistically significant differences in total blood loss, drain output, hemoglobin drop, incidence of transfusion, or DVT when comparing intra-articular and intravenous administration of TXA in TKA. This means that intra-articular application of TXA had a comparable effect on reducing blood loss and the transfusion rate without increasing the complication rate.

Intra-articular application of TXA has been investigated by many authors in recent years [11, 21-23]. As the drugs are applied predominantly to the joint cavity, the site of bleeding could achieve a higher therapeutic concentration. This could effectively limit blood loss with little or no systemic absorption or subsequent systemic side effects. Additionally, TXA is easy to administer in this way. In this study, compared with intravenous administration of TXA, intra-articular application is equally effective and safe to reduce blood transfusion after TKA, which means that this method could be widely used in clinical practice.

Though it has not been proven clinically, TXA could carry a high risk of thrombosis [24, 25]. Also, DVT is a common complication of TKA and can result in morbidity or even mortality when it progresses to PE [26]. Thus, surgeons should pay close attention to them. In comparison with intra- venous application of TXA, the intra-articular application was considered to feature less systemic absorption and a better local effect, so it may lead to a lower incidence of thrombosis. In this metaanalysis, DVTs were found in 1 of 305 patients $(0.3 \%)$ in the intra-articular group and in 3 of 371 patients $(0.8 \%)$ in the intravenous group. It seems that intravenous application of TXA is associated with a higher risk of DVTs; however, this difference is not statistically significant. This result could be due to the rare incidence of DVT or the relatively small sample size. Therefore, we cannot draw a definite conclusion yet, and corresponding findings require further confirmation. Also, the incidence of PE did not show a significant difference because no incident of PE was reported in any study. Further large-scale studies should also pay attention to this complication.

In the process of pooling some of the outcomes, substantial heterogeneity was observed among these studies, which was not surprising given the differences in characteristics of populations, doses of drug, and various methods of injecting TXA. Our sensitivity analyses suggested that the trial conducted by Sarzaeem et al. [15] probably contributed to the heterogeneity. This study differed from the others in some aspects. A major difference is the way of injecting TXA. Unlike other trials, TXA was injected through the drain in some patients instead of direct irrigation. This way had the advantage of topical application of TXA into the surgical field, and could result in significantly smaller amounts of post-operative blood loss, but it did not seem to be more effective than the other method to reduce the hemoglobin drop. However, this conclusion was derived from only one study. In the future, one may focus on this special method of administration of TXA. More well-performed RCTs could be performed to verify whether this method is better than the other way.

This meta-analysis has several potential limitations. First, we included only RCTs in an attempt to obtain reliable results. However, all these trials had methodological flaws, such as failure to blind the outcome assessor, or neglect of allocation con- 
cealment. Consequently, the quantitative results of this review should be interpreted with caution. Second, these trials included different administration protocols. TXA was injected at various doses and different times. We combined subgroups into a single sample size as the Cochrane Handbook suggested, but did not perform subgroup analysis because of the rather small numbers of studies. Third, the sample sizes in some studies were relatively small. Compared with the studies having a large sample size, studies with a small sample size may overestimate the true result. A large sample study may better reflect a true outcome because of its sufficient statistical power.

Further studies should focus on the following points. First, there is a need to standardize a protocol for the intravenous regimens of TXA (i.e., dosage, timing, and duration of administration) since great variability exists in the literature. Next, there is a lack of a clear, standardized protocol of intra-articular administration of TXA, and relevant studies are needed. Finally, further RCTs should not only improve the study quality but also enlarge the sample size, and this could help to investigate rare complications.

In conclusion, in this meta-analysis of RCTs comparing the intra-articular and intravenous administration of TXA in TKA, current evidence shows that intra-articular application has a comparable effect on reducing blood loss and the transfusion rate without increasing the complication rate. Nevertheless, the results should be interpreted with caution. Further large-scale, well-designed RCTs on this topic are still needed.

\section{Acknowledgments}

Yaming Liu and Fantao Meng contributed equally to this work.

\section{Conflict of interest}

The authors declare no conflict of interest.

\section{References}

1. Fujimoto H, Ozaki T, Asaumi K et al. Blood loss in patients for total knee arthroplasty. Knee Surg Sports Traumatol Arthrosc 2003; 11: 149-54.

2. Park JH, Rasouli MR, Mortazavi SM, et al. Predictors of perioperative blood loss in total joint arthroplasty. J Bone Joint Surg Am 2013; 95: 1777-83.

3. Fiebig E. Safety of the blood supply. Clin Orthop Relat Res 1998; 357: 6-18.

4. Vamvakas EC, Blajchman MA. Transfusion-related mortality: the ongoing risks of allogeneic blood transfusion and the available strategies for their prevention. Blood 2009; 113: 3406-17.

5. Longstaff $C$. Studies on the mechanisms of action of aprotinin and tranexamic acid as plasmin inhibitors and antifibrinolytic agents. Blood Coagul Fibrinolysis 1994; 5: 537-42.
6. Tan J, Chen H, Liu Q, et al. A meta-analysis of the effectiveness and safety of using tranexamic acid in primary unilateral total knee arthroplasty. J Surg Res 2013; 184: 880-7.

7. Charoencholvanich K, Siriwattanasakul P. Tranexamic acid reduces blood loss and blood transfusion after TKA: a prospective randomized controlled trial. Clin Orthop Relat Res 2011; 469: 2874-80.

8. Maniar RN, Kumar G, Singhi T, et al. Most effective regimen of tranexamic acid in knee arthroplasty: a prospective randomized controlled study in 240 patients. Clin Orthop Relat Res 2012; 470: 2605-12.

9. Camarasa MA, Olle G, Serra-Prat M, et al. Efficacy of aminocaproic, tranexamic acids in the control of bleeding during total knee replacement: a randomized clinical trial. Br J Anaesth 2006; 96: 576-82.

10. Sabatini L, Atzori F, Revello S, et al. Intravenous use of tranexamic acid reduces postoperative blood loss in total knee arthroplasty. Arch Orthop Trauma Surg 2014; 134: 1609-14.

11. Wong J, Abrishami A, El Beheiry $\mathrm{H}$, et al. Topical application of tranexamic acid reduces postoperative blood loss in total knee arthroplasty: a randomized, controlled trial. J Bone Joint Surg Am 2010; 92: 2503-13.

12. Higgins JPT. In: Green S (eds) Cochrane handbook for systematic reviews of interventions. Version 5.1.0 [updated March 2011]. The Cochrane Collaboration. http:// www.cochrane-handbook.org.

13. Gomez-Barrena E, Ortega-Andreu M, Padilla-Eguiluz NG, et al. Topical intra-articular compared with intravenous tranexamic acid to reduce blood loss in primary total knee replacement: a double-blind, randomized, controlled, noninferiority clinical trial. J Bone Joint Surg Am 2014; 96: 1937-44.

14. Patel JN, Spanyer JM, Smith LS, et al. Comparison of intravenous versus topical tranexamic acid in total knee arthroplasty: a prospective randomized study. J Arthroplasty 2014; 29: 1528-31.

15. Sarzaeem MM, Razi M, Kazemian G, et al. Comparing efficacy of three methods of tranexamic acid administration in reducing hemoglobin drop following total knee arthroplasty. J Arthroplasty 2014; 29: 1521-4.

16. Seo JG, Moon YW, Park SH, et al. The comparative efficacies of intra-articular and IV tranexamic acid for reducing blood loss during total knee arthroplasty. Knee Surg Sports Traumatol Arthrosc 2013; 21: 1869-74.

17. Soni A, Saini R, Gulati A, et al. Comparison between intravenous and intra-articular regimens of tranexamic acid in reducing blood loss during total knee arthroplasty. J Arthroplasty 2014; 29: 1525-7.

18. Li Y, Zhou C, Zhou X, et al. Pregnancy-associated plasma protein A predicts adverse vascular events in patients with coronary heart disease: a systematic review and meta-analysis. Arch Med Sci 2013; 9: 389-97.

19. Mozaffari S, Nikfar S, Abdollahi M. Efficacy and tolerability of renzapride in irritable bowel syndrome: a meta-analysis of randomized, controlled clinical trials including 2528 patients. Arch Med Sci 2014; 10: 10-8.

20. Zhu J, Su X, Li G, et al. The incidence of acute myocardial infarction in relation to overweight and obesity: a meta-analysis. Arch Med Sci 2014; 10: 855-62.

21. Zhao-Yu C, Yan G, Wei C, et al. Reduced blood loss after intra-articular tranexamic acid injection during total knee arthroplasty: a meta-analysis of the literature. Knee Surg Sports Traumatol Arthrosc 2014; 22: 3181-90.

22. Zhang Y, Fu X, Liu WX, et al. Safety and efficacy of intra-articular injection of tranexamic acid in total knee arthroplasty. Orthopedics 2014; 37: e775-82. 
23. Alshryda S, Mason J, Vaghela M, et al. Topical (intra-articular) tranexamic acid reduces blood loss and transfusion rates following total knee replacement: a randomized controlled trial (TRANX-K). J Bone Joint Surg Am 2013; 95: 1961-8.

24. Sperzel M, Huetter J. Evaluation of aprotinin and tranexamic acid in different in vitro and in vivo models of fibrinolysis, coagulation and thrombus formation. J Thromb Haemost 2007; 5: 2113-8.

25. Upadhyay SP, Mallick PN, Jagia M, et al. Acute arterial thrombosis associated with inadvertent high dose of tranexamic acid. Indian J Crit Care Med 2013; 17: 237-9.

26. Bosque J Jr, Coleman SI, Di Cesare P. Relationship between deep vein thrombosis and pulmonary embolism following THA and TKA. Orthopedics 2012; 35: 228-33; quiz 34-5. 